\title{
Protective effect of rifampicin and clindamycin impregnated devices against Staphylococcus spp. infection after cerebrospinal fluid diversion procedures
}

\author{
Raquel Gutiérrez-González ${ }^{1 *}$, Gregorio R Boto ${ }^{1}$, Cristina Fernández-Pérez², Náyade del Prado²
}

\begin{abstract}
Background: Infection is a major complication of cerebrospinal fluid shunting procedures. The present report assesses the efficacy of such catheters in both shunts and external ventricular drains (EVDs) against infection and particularly against Staphylococcus spp. infection.

Methods: All shunt and EVD procedures performed by means of antibiotic-impregnated catheters (AICs) and nonAICs during the period of study were registered. In cases of shunt procedures, a minimal follow-up of 90 days was considered, as well as de novo insertion and catheter revisions. Single valve revisions were not included. In cases of EVD procedures, those catheters removed before the fifth post-insertion day were not included. A total of 119 cerebrospinal fluid shunting procedures performed with AICs were studied in comparison with 112 procedures performed by means of non-AlCs.
\end{abstract}

Results: Antibiotic-impregnated catheters were associated with a significant decrease in both overall and staphylococcal infection ( $p=0.030$ and $p=0.045$, respectively). The number needed to treat for AICs was 8 to prevent one infection and 14 to prevent one staphylococcal infection. When comparing with shunts, the use of EVDs was associated with a 37-fold increased likelihood of infection.

Conclusions: Antibiotic-impregnated catheters are a safe and helpful tool to reduce CSF shunting device-related infections.

\section{Background}

Infection is a major complication of cerebrospinal fluid (CSF) shunting devices. It involves higher morbidity and mortality for patients but higher costs for the hospital as well [1-10]. In the last decades preventive measures have focused on surgical technique, the use of peri-operative antibiotic prophylaxis and implanted devices. Catheters coverage with antibiotics or antiseptics has been one of the latest measures to be considered [11-35]. The aim of such measure is the slow delivery of the drug along the early postoperative period (which is theoretically the moment of higher risk) in order to avoid bacterial

\footnotetext{
* Correspondence: rgutierrezgonzalez@yahoo.es

'Department of Neurosurgery, Hospital Universitario Clínico San Carlos. Prof. Matin Lagos s/n, 28040 Madrid, Spain

Full list of author information is available at the end of the article
}

adherence to the catheter $[18,36,37]$. One of the first studies in this regard was published by Gower et al. [38] in 1985. The author employed catheters soaked up in Bacitracin A for 30 minutes, which resulted in a reduction of $54 \%$ of Staphylococcus epidermidis adherence to the catheter surface.

The development of CSF shunting devices impregnated with antiseptic or antibiotic agents has focused on preventing Staphylococcus spp. infections and particularly those ones caused by biofilm-producer Staphylococci strains, since these latter have been shown to be the main causative pathogens [39]. Although many authors defend the protective effect of AICs against infection in shunt procedures, there is short experience with external ventricular drains (EVDs). Besides that, only overall infection effect has been considered in most

\section{C) Biomed Central}


of the reports published to date and concerning the protective effect of AICs [11-15,18,19,25-27,29].

Clinical observation at our centre has led to believe that AICs are not only associated with a lower risk of staphylococcal infection, but to a higher risk of gramnegative bacilli (GNB) infection. This suspicion was partially confirmed in a preliminary study carried out at our centre [17]. The aim of the present study is to assess the efficacy of rifampicin and clindamycin impregnated CSF shunting devices against infection and particularly staphylococcal infection, as well as the effect of such catheters against GNB infection.

\section{Methods}

A single-centre, retrospective cohort study was designed to assess the efficacy of EVDs and shunts impregnated with rifampicin and clindamycin against infection (Bactiseal; Codman, Johnson \& Johnson, Raynham, MA, USA) when comparing them with non-impregnated devices.

\section{Patients selection}

All patients who underwent CSF shunt placement at our centre during the period of study from January $1^{\text {st }}$ 2004 to October $31^{\text {st }} 2008$ were reported. The procedures included both de novo insertion and shunt revisions (ventricular catheter, distal catheter or full revision). Single valve substitution was not included, as this part of the shunt is never impregnated and so, individual substitution should not influence in the event to be studied. A minimal follow-up of 90 days was considered. All patients who underwent an EVD insertion at our centre and kept the catheter for at least 5 days during the period of study from January $1^{\text {st }} 2006$ to October $31^{\text {st }} 2008$ were also included. Emergency and elective procedures were considered. Both dates of initial data collection correspond to the introduction of AICs in the regular clinical practice at our centre. Prior approval for AICs use was obtained from the institutional review board. Procedures were assigned to the treatment cohort when rifampicin $(0.054 \%)$ and clindamycin $(0.15 \%)$ impregnated catheters ("Bactiseal"; Codman, Johnson \& Johnson, Raynham, MA, USA) were employed and to the control cohort when non-AICs were implanted.

The presence of known allergy to rifampicin or clindamycin was the only strict exclusion criterion for the insertion of AICs. Clinical indication for shunt procedures was CSF shunting in every case. In EVDs, need of intracranial pressure monitoring was also included. The choice of AICs versus non-AICs was a decision solely made by the neurosurgeon in charge in all cases. No changes were made in surgical technique or peri- operative patient care. Written informed consent was obtained from patients or representatives in every elective procedure and when possible in emergency procedures.

A total of 231 procedures (119 shunts and 112 EVDs) performed in 171 patients were included for final analysis. Antibiotic-impregnated catheters were employed in 119 of them, using non-AICs in the 112 remaining procedures.

\section{Dependent variable: infection}

Infection was defined by positive result of CSF or/and surgical wound exudation culture, independently from catheter culture result. Positive result required the same microorganism grew on two consecutive positive samples when contamination was suspected.

\section{Independent variables}

Epidemiological, clinical and surgical variables were registered from every procedure included in the database (Table 1).

\section{Statistical analysis}

Database information was processed and analyzed by means of SPSS 15.0 for Windows.

\section{Descriptive statistics}

Numerical variables represented by the mean were contrasted with U Mann-Whitney test whereas those represented by the median were contrasted with Median test. Chi-square test or Exact Fisher test were used for categorical variables.

\section{Analytic statistics}

The proportion of infected devices as a function of the length of time they had been in place were compared between both cohorts by means of univariate Cox regression analysis and log-rank test on Kaplan-Meier estimates. Infection-free survival was analyzed by means of multivariate Cox regression model in order to estimate the simultaneous effects of independent variables on the incidence of device-related infection. Proportional hazard ratios (HRs) with 95\% confidence intervals (CIs) were calculated.

A stratified analysis depending on the type of device placed (EVD versus shunt) was performed in order to adjust for possible confounding variables. In the multivariate analysis concerning shunts, and with the aim of preserving the test statistical power due to the low incidence of infectious events, the most relevant confounding variable was identified. Then, the independent variable to be studied (AICs) and those variables that were significant at a $p$ value of 0.05 or less in the univariate Cox analysis were entered in a stepwise fashion into multivariate Cox regression models and tested for an independent effect. 
Table 1 Independent variables

\begin{tabular}{|c|c|}
\hline Shunts & EVDs \\
\hline EPIDEMIOLOGICAL VARIABLES & EPIDEMIOLOGICAL VARIABLES \\
\hline Age & Age \\
\hline$\leq 6$ months & $\leq 6$ months \\
\hline 7 months-14 years & 7 months -14 years \\
\hline 15-69 years & 15-69 years \\
\hline$\geq 70$ years & $\geq 70$ years \\
\hline Sex & Sex \\
\hline CLINICAL VARIABLES & CLINICAL VARIABLES \\
\hline CSF infection previous 6 months & Diagnosis \\
\hline Previous shunt & -Traumatic brain injury \\
\hline Diagnosis & -Vascular disease \\
\hline -Traumatic brain injury & -Haemorrhagic CVA +/- intraventricular haemorrhage \\
\hline -Vascular disease & -Tumour \\
\hline -Haemorrhagic CVA +/- intraventricular haemorrhage & -Premature intraventricular haemorrhage \\
\hline -Tumour & -Others (malformative, infectious, post-surgical causes) \\
\hline -Premature intraventricular haemorrhage & Follow-up \\
\hline \multicolumn{2}{|l|}{-Normal-pressure hydrocephalus } \\
\hline \multicolumn{2}{|l|}{-Others (malformative, infectious, post-surgical causes) } \\
\hline \multicolumn{2}{|l|}{ Follow-up } \\
\hline \multicolumn{2}{|l|}{ SURGICAL VARIABLES } \\
\hline \multicolumn{2}{|l|}{ Type of surgery } \\
\hline \multicolumn{2}{|l|}{-De novo insertion } \\
\hline \multicolumn{2}{|l|}{-Proximal revision } \\
\hline \multicolumn{2}{|l|}{-Distal revision } \\
\hline -Full revision & \\
\hline
\end{tabular}

EVD: external ventricular drain; CSF: cerebrospinal fluid; CVA: cerebrovascular accident.

All percentages were calculated per procedure. Considered level of significance was $5 \%$. All $p$ values were based on two-tailed tests of significance.

\section{Results}

A total of 231 procedures performed in 171 patients were included for final analysis. In 112 procedures an EVD was inserted and in the remaining 119 procedures a shunt was placed, including 112 ventriculoperitoneal shunts, 2 ventriculoatrial shunts, 4 cyst-peritoneal shunts and 1 subduro-peritoneal shunt. In 119 of them AICs were employed, using non-AICs in the 112 remaining procedures. Both cohorts were homogeneous for the aforementioned independent variables except for the type of CSF shunting device employed (shunt versus EVD) and the follow-up (Table 2). In the control cohort, EVDs percentage was significantly higher $(p=0.005)$ and, therefore, median follow-up was shorter $(p=0.002)$.

Infection was confirmed in 29 cases, 8 of them in the treatment cohort and the remaining 21 in the control cohort (Table 3). Staphylococcus epidermidis was the main causative agent (51.7\%), followed by GNB (37.9\%) and other agents $(27.6 \%)$. Three EVDs (two of them were AICs) were infected by multiple microorganisms, being at least one of them a Staphylococcus spp. or a GNB.

Overall infection rate was $12.6 \%$. Univariate analysis showed significant differences between the treatment and the control cohorts (6.7\% against $18.8 \%$, respectively; $p=0.006$ ). Staphylococcal infection rate was $6.9 \%$, being the differences observed between both cohorts significant as well (3.4\% in the treatment cohort against $10.7 \%$ in the control cohort; $p=0.028$ ). However, GNB infection rate did not increase in the treatment cohort $(p=0.303)$. After adjusting for follow-up by means of Kaplan-Meier curve and univariate Cox regression analysis, significant differences were shown as well (Figure 1). An explicative multivariate analysis using Cox regression model confirmed the decrease in overall and Staphylococcal infection rates when using AICs (HR 0.41; CI 95\% $0.18-0.96 ; p=0.030$ and HR 0.33; CI 95\% 0.10-1.05; $p=$ 0.045 , respectively). Thus, AICs were associated with a relative decrease of $59 \%$ in overall infection rate and a relative decrease of $67 \%$ in Staphylococcal infection rate. The number needed to treat (NNT) to prevent one infection was 8 . The NNT to prevent one Staphylococcal infection was 14. 
Table 2 Baseline characteristics of all the procedures included for analysis: Cohorts' comparison

\begin{tabular}{|c|c|c|c|}
\hline \multicolumn{4}{|c|}{ No. PROCEDURESS $(\%)(n=231)$} \\
\hline VARIABLES & TREATMENT COHORT $(n=119)$ & CONTROL COHORT $(n=112)$ & $p$ value \\
\hline Type of device EVD & $47(39.5)$ & $65(58.0)$ & 0.005 \\
\hline Age: & & & 0.600 \\
\hline$\leq 6$ months & $12(10.1)$ & $10(8.9)$ & NS \\
\hline 7 months- 14 years & $10(8.4)$ & $15(13.4)$ & NS \\
\hline 15-69 years & $71(59.7)$ & $67(59.8)$ & NS \\
\hline$\geq 70$ years & $26(21.8)$ & $20(17.9)$ & NS \\
\hline Sex Male & $68(57.1)$ & $64(57.1)$ & 1 \\
\hline Diagnosis: & & & 0.182 \\
\hline Traumatic brain injury & $8(6.7)$ & $10(8.9)$ & NS \\
\hline Vascular disease & $17(14.3)$ & $24(21.4)$ & NS \\
\hline$C V A+/-N H$ & $12(10.1)$ & $18(16.1)$ & NS \\
\hline Tumour & $33(27.7)$ & $18(16.1)$ & NS \\
\hline Premature IVH & $12(10.1)$ & $6(5.4)$ & NS \\
\hline Normal-pressure hydrocephalus & $17(14.3)$ & $16(14.3)$ & NS \\
\hline Others & $20(16.8)$ & $20(17.9)$ & NS \\
\hline Follow-up, median (IQR), days & $159(11-518)$ & $16(9-266)$ & 0.002 \\
\hline
\end{tabular}

$\mathrm{n}$ : sample size; EVD: external ventricular drain; CVA: cerebrovascular accident; IVH: intraventricular haemorrhage; IQR: interquartilic range; NS: non significant.

As a result of multivariate analysis an independent association between EVDs and infection risk was observed, being the likelihood of overall infection 37.03 folds higher for EVDs than shunts (CI 95\% 7.25-200.01; $p<0.001$ ), whereas the likelihood of Staphylococcal infection was 16.13 folds higher (CI 95\% 2.85-90.91; $p<$ 0.001) for EVDs than shunts.
All patients presented excellent tolerance to AICs. No local or systemic side-effects were described.

\section{Stratified analysis}

A stratified analysis was performed in order to minimize the impact of the type of CSF shunting device (EVD versus shunt) on infection.

Table 3 Aetiology of infections

\begin{tabular}{|c|c|c|c|c|c|c|c|}
\hline & & eatment coho & & & Control coh & & Total \\
\hline & EVD & Shunt & Total & EVD & shunt & total & \\
\hline Staphylococcus spp. & 2 & 2 & 4 & 7 & 5 & 12 & $16(55.2 \%)$ \\
\hline S. epidermidis & 2 & 2 & 4 & 7 & 4 & 11 & \\
\hline S. aureus & 0 & 0 & 0 & 0 & 1 & 1 & \\
\hline GNBs & 4 & 0 & 4 & 5 & 2 & 7 & $11(37.9 \%)$ \\
\hline$P$. aeruginosa & 0 & 0 & 0 & 0 & 1 & 1 & \\
\hline Acinetobacter spp. & 2 & 0 & 2 & 1 & 0 & 1 & \\
\hline Enterobacter spp. & 1 & 0 & 1 & 1 & 0 & 1 & \\
\hline E. coli & 0 & 0 & 0 & 1 & 0 & 1 & \\
\hline Sphingomonas spp. & 1 & 0 & 1 & 0 & 0 & 0 & \\
\hline Klebsiella spp. & 0 & 0 & 0 & 2 & 1 & 3 & \\
\hline Other microorganisms & 4 & 0 & 4 & 3 & 1 & 4 & $8(27.6 \%)$ \\
\hline Enterococcus spp. & 2 & 0 & 2 & 2 & 0 & 2 & \\
\hline Streptococcus spp. & 0 & 0 & 0 & 0 & 1 & 1 & \\
\hline Corynebacterium spp. & 1 & 0 & 1 & 1 & 0 & 1 & \\
\hline Candida spp. & 1 & 0 & 1 & 0 & 0 & 0 & \\
\hline Total (infection per procedure) & $6 / 47(12.8 \%)$ & $2 / 72(2.7 \%)$ & $8 / 119(6.7 \%)$ & $13 / 65(20 \%)$ & $8 / 47(17 \%)$ & $21 / 112(18.8 \%)$ & $29 / 231(12.6 \%)$ \\
\hline
\end{tabular}




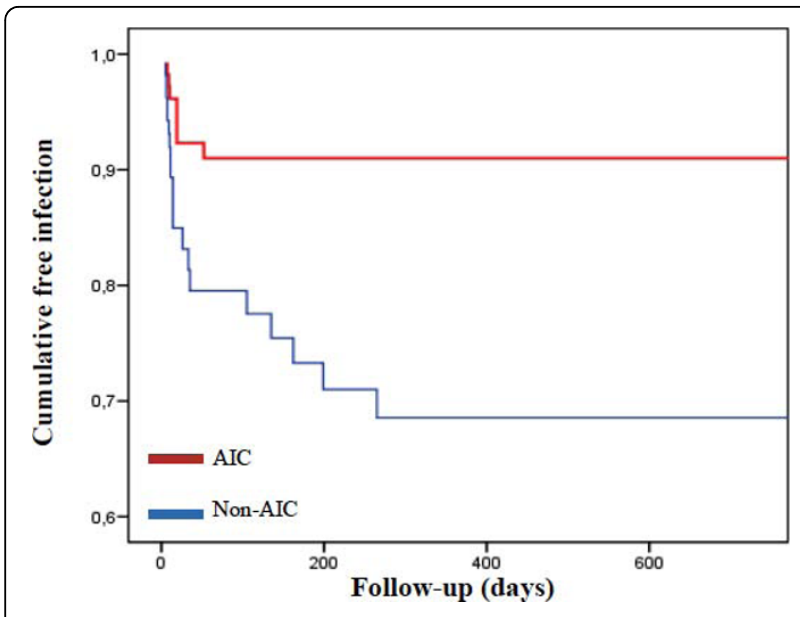

Figure 1 Kaplan-Meier curve. Cumulative freedom from infection according to antibiotic impregnation of the catheters. The risk of device-related infection was significantly lower in those procedures in which AICs were implanted compared with those procedures with non-AICS (HR 0.29; 95\% Cl 0.13-0.65; $p=0.003$ ).

\section{Shunts}

A total of 119 shunt procedures were included in this study, employing AICs in 72 of them (60.5\%). When comparing basal characteristics of both cohorts, a significantly higher percentage of patients between 15 and 69 years old and of those who underwent de novo insertion shunts was observed in the treatment cohort, while a significantly higher percentage of patients between 7 months old and 14 years old and of those who underwent full revision of the shunt was documented in the control cohort (Table 4). Ten infections were confirmed in this subgroup ( 2 in the treatment cohort and 8 in the control cohort; overall infection rate 8.4\%). Staphylococcus spp. was the most frequent causative agent (70\%), followed by GNB $(20 \%)$ and other microorganisms $(10 \%$. See Table 3). Overall infection rate was significantly lower when employing AICs $(2.8 \%$ in the treatment cohort against $17 \%$ in the control cohort; $p=0.014$ ). Staphylococcal infection rate was 5.9\% (7/119). When comparing control and treatment cohorts, the rate decreased from $10.6 \%$ to $2.8 \%(p=0.111)$. Only two GNB infections were confirmed (1.7\%), and both of them appeared in the control cohort $(p=0.303)$. Univariate Cox regression analysis showed a relative decrease of $84 \%$ in overall infection rate (HR 0.16; CI 95\% 0.03-0.73; $p=0.018$ ) in AICs procedures (Figure 2). In the multivariate analysis, the most important confounding factor (prior shunt) and the independent variable to be studied (AICs) were included in final models. Besides that, the independent variables associated with increasing infection rate after univariate analysis (prior CSF infection and full revision), were entered in a stepwise fashion. As a result, the protective effect of AICs against overall infection was significant in model 1 (HR 0.18 ; CI $95 \% 0.04-0.87 ; p=0.016)$ and marginally significant in model 2 (HR 0.25; CI 95\% 0.05-1.29; $p=0.071$ ).

\section{External ventricular drains}

A total of 112 procedures with EVDs were included, employing AICs in 47 of them (42\%). Both cohorts were homogeneous when comparing basal characteristics. Median length of ventriculostomy was 9 days in the treatment cohort and 10 days in the control cohort $(p=$ 0.679 ). Nineteen infections were confirmed in this subgroup (6 in the treatment cohort and 13 in the control cohort; overall infection rate 17\%). Staphylococcus spp. and GNB were isolated in similar percentage of positive cultures $(47.4 \%)$, while other microorganisms were isolated in $36.8 \%$ of positive cultures (Table 3). Overall infection rate was lower in the treatment cohort $(12.8 \%$, $6 / 47)$ than in the control cohort $(20 \%, 13 / 65 ; p=0.310)$. Staphylococcal infection rate was also lower in the study cohort (4.3\% against 10.8\%), but these differences were not statistically significant $(p=0.299)$. Gram-negative bacilli infection rate was similar in both cohorts $(p=1)$. Kaplan-Meier curve and univariate Cox regression analysis adjusting for length of ventriculostomy did not show significant differences between both cohorts (Figure 3).

\section{Discussion}

Prevention strategies designed to control device-related infectious complications have been determined in the last decades by the knowledge and comprehension of the mechanisms of infection involved. Given the importance that microorganism's adherence to CSF shunting catheters surface has achieved in the pathogenesis of infection, the most promising strategies are focusing on intrinsic treatment of the catheter surface in order to enhance resistance to colonization phenomena [40].

There are a rising number of studies that support the use of rifampicin and clindamycin impregnated catheters in shunt procedures in order to reduce not only the incidence but also the costs of device-related infectious complications [11-18,25-27,29-32]. However, only two of these studies mention the effect of AICs on Staphylococcal infection [16,17]. Experience with EVDs is shorter, since only two studies assessing rifampicin and clindamycin impregnated catheters efficacy have been published in the literature to date $[17,34]$. Besides that, two more studies evaluating minocycline and rifampicin impregnated EVDs have been reported [33,35].

The results obtained in the present retrospective study show a significant reduction in infection at our centre in those cases where AICs were used $(p=0.006)$ for CSF shunting procedures. A multivariate analysis of data, confirming that AICs are helpful and safe in reducing infectious complications rate $(p=0.030)$, was achieved 
Table 4 Baseline characteristics of shunt procedures: Cohorts' comparison

\begin{tabular}{|c|c|c|c|}
\hline \multirow[b]{2}{*}{ VARIABLES } & \multicolumn{2}{|c|}{ No. PROCEDURES (\%) $(n=119)$} & \multirow[b]{2}{*}{$p$ value } \\
\hline & TREATMENT COHORT $(\mathrm{n}=\mathbf{7 2})$ & CONTROL COHORT $(n=47)$ & \\
\hline Age: & & & 0.027 \\
\hline$\leq 6$ months & $6(8.3)$ & $8(17.0)$ & NS \\
\hline 7 months-14 years & $7(9.7)$ & $12(25.5)$ & 0.021 \\
\hline 15-69 years & $40(55.6)$ & $16(34.0)$ & 0.022 \\
\hline$\geq 70$ years & $19(26.4)$ & $11(23.4)$ & NS \\
\hline Sex Male & $38(52.7)$ & $30(63.8)$ & 0.234 \\
\hline CSF infection in previous 6 months & $16(22.2)$ & $10(21.3)$ & 0.903 \\
\hline Previous shunt & $16(22.2)$ & $19(40.4)$ & 0.033 \\
\hline Diagnosis: & & & 0.071 \\
\hline Traumatic brain injury & $4(5.6)$ & $0(0)$ & NS \\
\hline Vascular disease & $6(8.3)$ & $3(6.4)$ & NS \\
\hline$C V A+/-I V H$ & $1(1.4)$ & $0(0)$ & NS \\
\hline Tumour & $21(29.2)$ & $6(12.8)$ & NS \\
\hline Premature IVH & $6(8.3)$ & $5(10.6)$ & NS \\
\hline Normal-pressure hydrocephalus & $17(23.6)$ & $16(34.0)$ & NS \\
\hline Others & $17(23.6)$ & $17(36.1)$ & NS \\
\hline Type of surgery: & & & 0.001 \\
\hline De novo & $55(76.4)$ & $27(57.4)$ & 0.029 \\
\hline Proximal revision & $6(8.3)$ & $2(4.3)$ & NS \\
\hline Distal revision & $4(5.5)$ & $0(0)$ & NS \\
\hline Full revision & $7(9.7)$ & $18(38.3)$ & $<0.001$ \\
\hline Follow-up, median (IQR), days & $384.5(184-704.75)$ & $385(144-1085)$ & 0.910 \\
\hline
\end{tabular}

$\mathrm{n}$ : sample size; CSF: cerebrospinal fluid; CVA: cerebrovascular accident; IVH: intraventricular haemorrhage; IQR: interquartilic range; NS: non significant

with the aim of minimizing the impact of possible confounding factors (the most relevant one may be the type of CSF shunting device -internal versus external-). Moreover, a significant decrease in Staphylococcal infection rate was observed in both univariate $(p=0.028)$

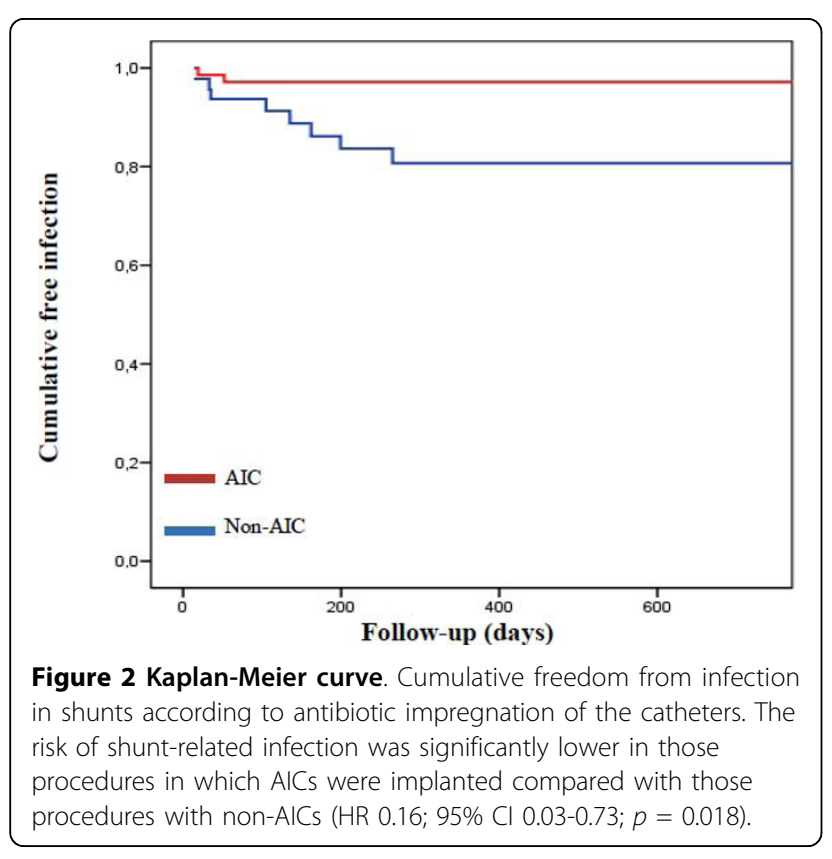

and multivariate $(p=0.045)$ analyses. The use of these catheters did not increase GNB infection rate. On the contrary, a trend to reduce the infection caused by these bacteria was observed, although the differences observed

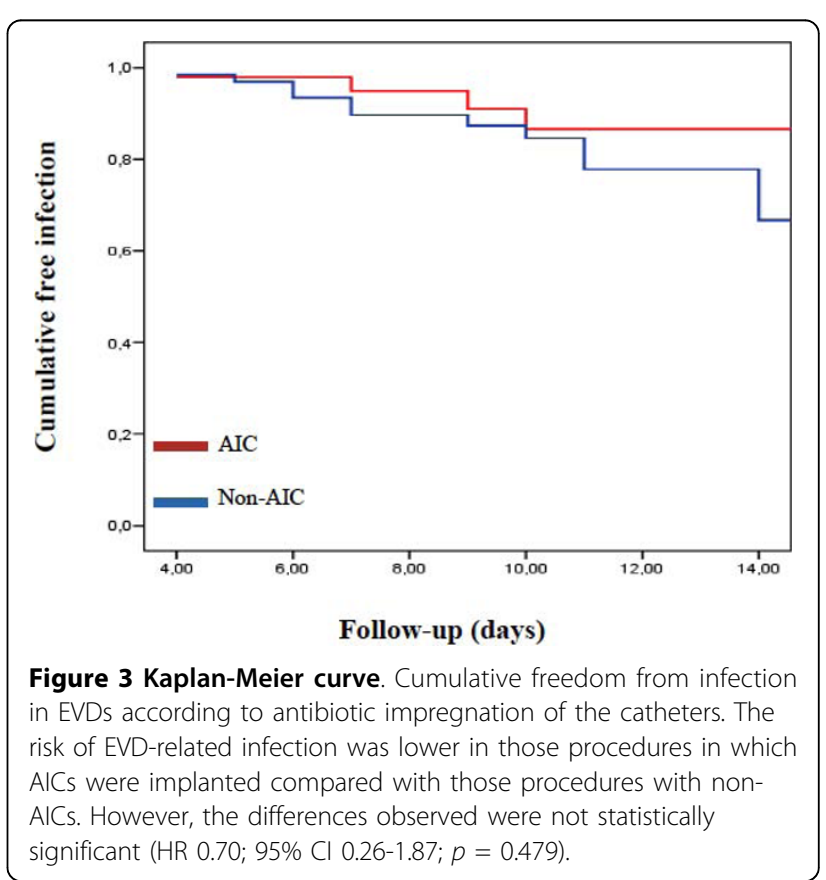


between both cohorts were not significant. In view of these results, rifampicin and clindamycin impregnated catheters in both shunt and EVD procedures are shown to be a helpful and safe tool to reduce and control the incidence of infection after their use.

Despite the fact that it was not one of the prefixed objectives of the study, multivariate analysis demonstrated that EVDs were 37.03-fold more likely to become infected than shunts, as well as 16.13-fold more likely to become infected by Staphylococcus spp. than shunts. Although it is widely accepted that EVDs risk of infection is higher than shunts risk, to our knowledge this is the first study that quantifies the increase in the likelihood of infection associated to the former. External ventricular drains removed before the fifth day following insertion were excluded from this study with the purpose of minimizing the false-negative rate, a bias that must be considered. However, the results hereby reported may approach the risk of infection assumed when making the decision of implanting an EVD instead of a shunt in certain patients.

A stratified analysis was performed depending on the type of CSF shunting device employed with the aim of minimizing as much as possible the impact of confounding factors. Thus, in the subgroup of shunts, rifampicin and clindamycin impregnated catheters were associated with a significant decrease in overall infection $(p=$ 0.014 , univariate analysis). After multivariate analysis, a marginally significant decrease in these complications was also observed, with a relative reduction of $75 \%$ in overall infection rate when employing AICs. These differences have also been reported by other authors $[16,29]$. Staphylococcal infection rate was importantly reduced too -from $10.6 \%$ to $2.8 \%$ - when inserting AICs. However this result was not statistically significant. This fact could be explained by the low incidence of infectious events, being necessary to increase the sample size to obtain statistically relevant differences. Besides that, the use of AICs did not increase GNB infection, a similarity observed in other studies results $[17,25]$.

Considering exclusively EVDs, AICs were associated with a decrease from $20 \%$ to $12.8 \%$ in overall infection rate and a decrease from $10.8 \%$ to $4.3 \%$ in Staphylococcal infection rate $(p=0.310$ and $p=0.299$, respectively), without increasing GNB infection rate. Once observed the results obtained after multivariate analysis of the whole sample, these findings could be explained by the small sample size given the low incidence of infectious events.

There are only two studies that have been published in the literature to date which compare the incidence of infection when employing rifampicin and clindamycin impregnated EVDs against control catheters [17,34]. Despite the fact that both studies point to the usefulness of these devices in reducing infectious complications, they include a small number of procedures. Besides that, the study carried out by Tamburrini et al. [34] includes a specific subgroup of patients suffering from hydrocephalus secondary to posterior fossa tumours. Similarly, the reports with minocycline and rifampicin impregnated catheters show a significant reduction in infection associated with the use of treated catheters $[33,35]$. However, a recent study reports a significant number of false-negative results from minocycline and rifampicin impregnated EVDs compared with non-antibiotic impregnated EVDs [41]. This potential bias has not been studied concerning rifampicin and clindamycin impregnated catheters.

Another consideration is that the presence of infection involves not only morbidity and mortality for the patient, but increasing costs for the hospital as well. One of the latest lines of research that remains incomplete is to determine if AICs reduce infection hospital costs, despite their higher price when comparing to non-AICs. Economical differences will be probably important, given the increased cost derived from treating a CSF device-related infection when considering intravenous antibiotic treatment, intensive care unit stay, new CSF shunting device or prolonged hospital stay. Although the difference in price between AICs and non-AICs is easily measurable (differences around $100 €$ in EVDs and $180 €$ in shunts), it is not so easy to quantify the hospital cost derived from an infectious event. This difficulty may be the main obstacle in designing a study to assess these costs. Three studies have been published in the literature in order to assess the impact of antibiotic-impregnated shunts on hospital costs. All of them suggest the economic effectiveness of the aforementioned systems $[13,14,30]$. However, no study has been performed with EVDs with this purpose, thus the economical impact of AICs in this field remains unknown.

Finally, the main limitations of this study derive from its retrospective design, as it does not provide the best level of scientific evidence to draw conclusions. Multivariate and stratified analyses were performed in order to avoid the impact of possible confounding factors. Besides that, data were exclusively collected by the first author of this study with the aim of giving consistency to data codification and in order to make database management easier.

\section{Conclusions}

The results obtained in this retrospective study suggest that AICs are a protective and safe tool against infection and, specifically, against Staphylococcus spp. infection. The number needed to treat for AICs is 8 to prevent one infection and 14 to prevent one staphylococcal 
infection. When comparing with shunts, the use of EVDs is associated with a 37-fold increased likelihood of infection. However, further prospective, randomized, controlled trials are required to confirm these results.

\section{Acknowledgements}

The authors thank Cristina Ruiz Quevedo for assistance in the translation of the manuscript. None of the authors have received any financial support for this study.

\section{Author details}

'Department of Neurosurgery, Hospital Universitario Clínico San Carlos. Prof. Matin Lagos s/n, 28040 Madrid, Spain. 'Department of Preventive Medicine, Hospital Universitario Clínico San Carlos. Prof. Matin Lagos s/n, 28040 Madrid, Spain.

\section{Authors' contributions}

RGG carried out data collection, participated in the design of the study and drafted the manuscript. GRB: conceived of the study, and participated in its design and coordination and helped to draft the manuscript. CFP: participated in the design of the study and performed the statistical analysis. $\mathrm{NdP}$ : participated in the design of the study and performed the statistical analysis. All authors read and approved the final manuscript.

\section{Competing interests}

The authors declare that they have no competing interests.

Received: 31 March 2010 Accepted: 12 October 2010 Published: 12 October 2010

\section{References}

1. Blount JP, Campbell JA, Haines SJ: Complications in ventricular cerebrospinal fluid shunting. Neurosurg Clin N Am 1993, 4:633-656.

2. Borgbjerg BM, Gjerris F, Albeck MJ, Borgesen SE: Risk of infection after cerebrospinal fluid shunt: an analysis of 884 first-time shunts. Acta Neurochir (Wien) 1995, 136:1-7.

3. George R, Leibrock L, Epstein M: Long-term analysis of cerebrospinal fluid shunt infections. A 25-year experience. J Neurosurg 1979, 51:804-811.

4. Kestle J, Drake J, Milner R, Sainte-Rose C, Cinalli G, Boop F, Piatt J, Haines S, Schiff S, Cochrane D, Steinbok P, MacNeil N: Long-term follow-up data from the Shunt Design Trial. Pediatr Neurosurg 2000, 33:230-236.

5. Kestle JR, Garton HJ, Whitehead WE, Drake JM, Kulkarni AV, Cochrane DD, Muszynski C, Walker ML: Management of shunt infections: a multicenter pilot study. J Neurosurg 2006, 105(Suppl 3):177-181.

6. Lenfestey RW, Smith PB, Moody MA, Clark RH, Cotten CM, Seed PC, Benjamin DK Jr: Predictive value of cerebrospinal fluid parameters in neonates with intraventricular drainage devices. J Neurosurg 2007, 107(Suppl 3):209-212.

7. Lyke KE, Obasanjo OO, Williams MA, O'Brien M, Chotani R, Perl TM: Ventriculitis complicating use of intraventricular catheters in adult neurosurgical patients. Clin Infect Dis 2001, 33:2028-2033.

8. Schoenbaum SC, Gardner P, Shillito J: Infections of cerebrospinal fluid shunts: epidemiology, clinical manifestations, and therapy. J Infect Dis 1975, 131:543-552.

9. Walters BC, Hoffman HJ, Hendrick EB, Humphreys RP: Cerebrospinal fluid shunt infection. Influences on initial management and subsequent outcome. J Neurosurg 1984, 60:1014-1021.

10. Wang KW, Chang WN, Shih TY, Huang CR, Tsai NW, Chang CS, Chuang YC, Liliang PC, Su TM, Rau CS, Tsai YD, Cheng BC, Hung PL, Chang CJ, Lu CH: Infection of cerebrospinal fluid shunts: causative pathogens, clinical features, and outcome. Jpn J Infect Dis 2004, 57:44-48.

11. Albanese A, De Bonis P, Sabatino G, Capone G, Marchese E, Vignati A, Maira G: Antibiotic-impregnated ventriculo-peritoneal shunts in patients at high risk of infection. Acta Neurochir (Wien) 2009, 151:1259-1263.

12. Aryan HE, Meltzer HS, Park MS, Bennett RL, Jandial R, Levy ML: Initial experience with antibiotic-impregnated silicone catheters for shunting of cerebrospinal fluid in children. Childs Nerv Syst 2005, 21:56-61.

13. Attenello FJ, Garces-Ambrossi GL, Zaidi HA, Sciubba DM, Jallo Gl: Hospital costs associated with shunt infections in patients receiving antibiotic- impregnated shunt catheters versus standard shunt catheters. Neurosurgery 2010, 66:284-289.

14. Eymann R, Chehab S, Strowitzki M, Steudel WI, Kiefer M: Clinical and economic consequences of antibiotic-impregnated cerebrospinal fluid shunt catheters. J Neurosurg Pediatrics 2008, 1:444-450.

15. Eymann R, Steudel WI, Kiefer M: Infection rate with application of an antibiotic-impregnated catheter for shunt implantation in children - a retrospective analysis. Klin Padiatr 2009, 221:69-73.

16. Govender ST, Nathoo N, van Deller JR: Evaluation of an antibioticimpregnated shunt system for the treatment of hydrocephalus. $J$ Neurosurg 2003, 99:831-839.

17. Gutiérrez-González R, Boto GR, González N, Viudez I, Pérez-Zamarrón A, Rivero-Garvía M: Effect of antibiotic-impregnated catheters on the incidence of infection after cerebrospinal fluid shunting. Med Clin (Barc) 2008, 131:121-124

18. Gutierrez-Gonzalez R, Boto GR: Do antibiotic-impreganted catheters prevent infection in CSF diversion procedures? Review of the literature. $J$ Infect 2010, 61:9-20.

19. Hampl JA, Weitzel A, Bonk C, Kohnen W, Roesner D, Jansen B: Rifampinimpregnated silicone catheters: a potential tool for prevention and treatment of CSF shunt infections. Infection 2003, 31:109-111.

20. Hayhurst C, Cooke R, Williams D, Kandasamy J, O'Brien DF, Mallucci CL: The impact of antibiotic-impregnated catheters on shunt infection in children and neonates. Childs Nerv Syst 2008, 24:557-562.

21. Izci Y, Secer H, Akay C, Gonul E: Initial experience with silver-impregnated polyurethane ventricular catheter for shunting of cerebrospinal fluid in patients with infected hydrocephalus. Neurol Res 2008, 31:234-237.

22. Kan P, Kestle J: Lack of efficacy of antibiotic-impregnated shunt systems in preventing shunt infection in children. Childs Nerv Syst 2007, 23:773-777.

23. Kaufmann AM, Lye T, Redekop G, Brevner A, Hamilton M, Kozey M, Easton D: Infection rates in standard vs. hydrogel coated ventricular catheters. Can J Neurol Sci 2004, 31:506-510

24. Lackner P, Beer R, Broessner G, Helbok R, Galiano K, Pleifer C, Pfausler B, Brenneis C, Huck C, Engelhardt K, Obwegeser AA, Schmutzhard E: Efficacy of silver nanoparticles-impregnated external ventricular drain catheters in patients with acute occlusive hydrocephalus. Neurocrit Care 2008, 8:360-365.

25. Parker SL, Attenello FJ, Sciubba DM, Garces-Ambrossi GL, Ahn E, Weingart J, Carson B, Jallo Gl: Comparison of shunt infection incidence in high-risk subgroups receiving antibiotic-impregnated versus standard shunts. Childs Nerv Syst 2009, 25:77-83.

26. Pattavilakom A, Xenos C, Bradfield O, Danks RA: Reduction in shunt infection using antibiotic impregnated CSF shunt catheters: an Australian prospective study. J Clin Neurosci 2007, 14:526-531.

27. Richards HK, Seeley HM, Pickard JD: Efficacy of antibiotic-impregnated shunt catheters in reducing shunt infection: data from de United Kingdom Shunt Registry. J Neurosurg Pediatr 2009, 4:389-393.

28. Ritz R, Roser F, Morgalla M, Dietz K, Tatagiba M, Will BE: Do antibioticimpregnated shunts in hydrocephalus therapy reduce the risk of infection? An observational study in 258 patients. BMC Infect Dis 2007, 7:38.

29. Sciubba DM, Stuart RM, McGirt MJ, Woodworth GF, Samdani A, Carson B, Jallo Gl: Effect of antibiotic-impregnated shunt catheters in decreasing the incidence of shunt infection in the treatment of hydrocephalus. $J$ Neurosurg 2005, 103(Suppl 2):131-136.

30. Sciubba DM, Lin L, Woodworth GF, McGirth MJ, Carson B, Jallo Gl: Factors contributing the medical costs of cerebrospinal fluid shunt infection treatment in pediatric patients with standard shunt components compared with those in patients with antibiotic impregnated components. Neurosurg Focus 2007, 22:E9.

31. Sciubba DM, McGirt MJ, Woodworth GF, Carson B, Jallo Gl: Prolonged exposure to antibiotic-impregnated shunt catheters does not increase incidence of late shunt infections. Childs Nerv Syst 2007, 23:867-871.

32. Sciubba DM, Noggle JC, Carson BS, Jallo Gl: Antibiotic-impregnated shunt catheters for the treatment of infantile hydrocephalus. Pediatr Neurosurg 2008, 44:91-96

33. Sloffer CA, Augspurger L, Wagenbach A, Lanzino G: Antimicrobialimpregnated external ventricular catheters: does the very low infection rate observed in clinical trials apply to daily clinical practice? Neurosurgery 2005, 56:1041-1044. 
34. Tamburrini G, Massimi L, Caldarelli M, Di Rocco C: Antibiotic impregnated external ventricular drainage and third ventriculostomy in the management of hydrocephalus associated with posterior cranial fossa tumours. Acta Neurochir (Wien) 2008, 150:1049-1056.

35. Zabramski JM, Whiting D, Darouiche RO, Horner TG, Olson J, Robertson C, Hamilton AJ: Efficacy of antimicrobial-impregnated external ventricular drain catheters: a prospective, randomized, controlled trial. J Neurosurg 2003, 98:725-730.

36. Bayston R, Grove N, Siegel J, Lawellin D, Barsham S: Prevention of hydrocephalus shunt catheter colonisation in vitro by impregnation with antimicrobials. J Neurol Neurosurg Psychiatry 1989, 52:605-609.

37. Bayston R, Lambert E: Duration of protective activity of cerebrospinal fluid shunt catheters impregnated with antimicrobial agents to prevent bacterial catheter-related infection. J Neurosurg 1997, 87:247-251.

38. Gower DJ, Gower VC, Richardson SH, Kelly DL Jr: Reduced bacterial adherence to silicone plastic neurosurgical prosthesis. Pediatr Neurosci 1985, 12:127-133.

39. Bayston R, Penny $S$ : Excessive production of mucoid substance in staphylococcus SIIA: a possible factor in colonisation of holter shunts. Dev Med Child Neurol Suppl 1972, 27:25-28.

40. Bayston R, Barsham S: Catheter colonisation: a laboratory model suitable for aetiological, therapeutic and preventive studies. Med Lab Sci 1988, 45:235-239.

41. Stevens EA, Palavecino E, Sherertz RJ, Shihabi Z, Couture DE: Effects of antibiotic-impregnated external ventricular drains on bacterial culture results: an in vitro analysis. J Neurosurg 2010, 113(1):86-92.

\section{Pre-publication history}

The pre-publication history for this paper can be accessed here: http://www.biomedcentral.com/1471-2377/10/93/prepub

doi:10.1186/1471-2377-10-93

Cite this article as: Gutiérrez-González et al: Protective effect of rifampicin and clindamycin impregnated devices against Staphylococcus spp. infection after cerebrospinal fluid diversion procedures. BMC Neurology 2010 10:93.

\section{Submit your next manuscript to BioMed Central and take full advantage of:}

- Convenient online submission

- Thorough peer review

- No space constraints or color figure charges

- Immediate publication on acceptance

- Inclusion in PubMed, CAS, Scopus and Google Scholar

- Research which is freely available for redistribution 